\title{
Impact of being underweight on the long-term outcomes of patients with gastric cancer
}

\author{
Kazuhiro Migita $^{1} \cdot$ Tomoyoshi Takayama $^{1} \cdot$ Sohei Matsumoto $^{1} \cdot$ Kohei Wakatsuki $^{1} \cdot$ \\ Tetsuya Tanaka ${ }^{1}$ Masahiro Ito ${ }^{1} \cdot$ Tomohiro Kunishige $^{1} \cdot$ Hiroshi Nakade $^{1}$ • \\ Yoshiyuki Nakajima ${ }^{1}$
}

Received: 24 June 2014/ Accepted: 1 August 2015/Published online: 23 August 2015

(C) The International Gastric Cancer Association and The Japanese Gastric Cancer Association 2015

\begin{abstract}
Background The aim of this study was to investigate the impact of being underweight on the long-term outcomes of gastric cancer patients.

Methods This study reviewed the medical records of 638 patients with gastric cancer who underwent gastrectomy between January 2003 and December 2011. The patients were divided into three groups according to the WHO classification: underweight (BMI $<18.5 \mathrm{~kg} / \mathrm{m}^{2}$ ), normal weight (BMI $\geq 18.5$ and $<25 \mathrm{~kg} / \mathrm{m}^{2}$ ), and overweight (BMI $\geq 25 \mathrm{~kg} / \mathrm{m}^{2}$ ). A multivariate analysis was performed to identify prognostic factors.

Results The mean BMI immediately before surgery was $22.5 \mathrm{~kg} / \mathrm{m}^{2}$ (standard deviation, $3.3 \mathrm{~kg} / \mathrm{m}^{2}$ ). According to the BMI subgroup, 73 patients $(11.4 \%)$ were underweight, 431 patients $(67.6 \%)$ were of normal weight, and 134 patients $(21 \%)$ were overweight. The 5-year overall survival (OS) rate was $66.6 \%$ in the underweight patients, $81.3 \%$ in the normal weight patients, and $79.9 \%$ in the overweight patients $(P=0.001)$. The OS rate was significantly lower in the underweight patients than in the normal weight and overweight patients among those with stage I disease, and it was also lower than in the normal weight patients among those with stage II and III disease. In the multivariate analysis, being underweight was found to be an independent predictor of OS, but it was not an independent predictor among patients with stage II and III disease.
\end{abstract}

Kazuhiro Migita

kmigita@naramed-u.ac.jp

1 Department of Surgery, Nara Medical University, 840 Shijo-cho, Kashihara, Nara 634-8522, Japan
Conclusions Being underweight is a simple and reliable predictor of a worse long-term outcome among gastric cancer patients. Being underweight is considered to be associated with a higher risk of non-cancer death.

Keywords Body mass index · Underweight · Gastric cancer · Prognosis

\section{Introduction}

To date, a number of studies have investigated the influence of various nutritional parameters on surgical outcomes, and preoperative nutritional status has been shown to be associated with the incidence of postoperative complications [1-3]. In cancer patients, a low nutritional status has been suggested to carry a higher risk of both cancerrelated and non-cancer death $[3,4]$. Therefore, the patient's nutritional status should be taken into consideration when planning cancer treatment.

The body mass index (BMI) is a simple and effective index of nutritional status. The effect of BMI on the longterm outcomes of gastric cancer patients has previously been reported, although with conflicting results. In addition, overweight status and obesity have been demonstrated to be associated with a worse prognosis, partly the result of a significantly lower number of retrieved lymph nodes [5]. In contrast, some studies have reported no associations between BMI and survival [6,7], although others have documented that being overweight or obese correlates with improved survival $[8,9]$. These studies focused primarily on the prognostic value of being overweight or obese. On the other hand, recent studies have shown that being underweight is associated with a worse prognosis in various types of cancers, including colon cancer [10], 
hepatocellular carcinoma [11], nasopharyngeal carcinoma [12], breast cancer [13, 14], cervical carcinoma [15], and urothelial carcinoma [16]. However, there is currently little information regarding the prognostic value in gastric cancer patients of being underweight [17]. Therefore, we retrospectively investigated the correlation between being underweight and various clinicopathological factors and assessed the impact of being underweight on long-term outcomes in gastric cancer patients.

\section{Patients and methods}

\section{Patients}

A total of 761 patients with histologically confirmed gastric cancer underwent gastrectomy between January 2003 and December 2011 at Nara Medical University Hospital. We excluded 63 patients treated with R1 and R2 resection, 45 patients who underwent preoperative chemotherapy, 13 patients who had stage IV disease, and 2 patients whose perioperative data were unavailable. Therefore, 638 patients were analyzed in this study.

\section{Data}

In the present study, BMI was calculated as the patient's weight (in kilograms) immediately before surgery divided by the square of the height (in meters). The patients were then divided into three groups-underweight (BMI $<18.5 \mathrm{~kg} / \mathrm{m}^{2}$ ), normal weight (BMI $\geq 18.5$ and $<25 \mathrm{~kg} /$ $\mathrm{m}^{2}$ ), and overweight (BMI $\geq 25 \mathrm{~kg} / \mathrm{m}^{2}$ ) - according to the World Health Organization (WHO) classification [18].

We further obtained the subjects' clinicopathological and surgical findings from their medical records. The clinicopathological findings included patient age, sex, preexisting comorbidities (including cardiovascular disease, diabetes mellitus, and chronic renal failure), tumor depth, lymph node metastasis, and pathological cancer stage. A total of 133 patients $(20.8 \%)$ received postoperative adjuvant chemotherapy with an oral 5-fluorouracilbased regimen. The stage of gastric cancer was classified according to the 7th edition of the American Joint Committee on Cancer TNM classification system [19]. The surgical findings included duration of surgery, amount of blood loss, use of perioperative blood transfusions, number of lymph nodes removed, and length of postoperative hospital stay. The incidence of postoperative complications was also evaluated, and the severity of complications was defined according to the Clavien-Dindo classification [20].

In addition, we collected data from blood tests performed immediately before the procedure, including carcinoembryonic antigen (CEA), carbohydrate antigen
(CA)19-9, total lymphocyte count in the peripheral blood, and serum albumin and hemoglobin levels. Thereafter, the prognostic nutritional index (PNI) was determined using the following formula: $10 \times$ serum albumin value $(\mathrm{g} /$ dl) $+0.005 \times$ total lymphocyte count in the peripheral blood $\left(/ \mathrm{mm}^{3}\right)[3]$.

\section{Statistical analysis}

Categorical variables are presented as numbers and percentages, and groups were compared using the chi-square test. Continuous variables are expressed as the mean and standard deviation, and means were compared using a oneway analysis of variance (ANOVA). A post hoc analysis was also performed using the Tukey's or the GamesHowell procedure.

At the time of the final follow-up (May 2014), the mean follow-up period was 50.6 months. Overall survival (OS) was defined as the duration from surgery to death, and disease-specific survival (DSS) was defined as the duration from surgery to death from gastric cancer. The survival curves were estimated according to the KaplanMeier method, and differences between the curves were analyzed using the log-rank test. The univariate and multivariate hazard ratios were calculated using a Cox proportional hazard model. All significant variables in the univariate analysis were entered into a multivariate analysis. A $P$ value $<0.05$ was considered to be significant, and confidence intervals (CI) were calculated at the $95 \%$ level. The statistical analyses were performed using the SPSS software program, version 19.0 (SPSS, Chicago, IL, USA).

\section{Results}

\section{BMI and clinicopathological characteristics}

Mean BMI immediately before surgery was $22.5 \mathrm{~kg} / \mathrm{m}^{2}$ (standard deviation, $3.3 \mathrm{~kg} / \mathrm{m}^{2}$ ). According to the WHO BMI subgroups, 73 patients $(11.4 \%)$ were underweight, 431 patients $(67.6 \%)$ were of normal weight, and 134 patients $(21 \%)$ were overweight.

The relationships between BMI and the clinicopathological characteristics are shown in Table 1. Chronic renal failure was more common among the underweight patients than in the other groups $(P=0.031)$. There were statistically significant differences between the groups in terms of tumor depth $(P=0.014)$; high baseline CEA $(P=0.011)$ and CA19-9 $(P=0.001)$ levels were more frequently observed among the underweight patients than among the normal weight or overweight patients. Statistically significant differences were also observed between the groups 
Table 1 Clinicopathological characteristics according to body mass index (BMI) group

\begin{tabular}{|c|c|c|c|c|c|}
\hline Variables & Total & Underweight $(n=73)$ & Normal weight $(n=431)$ & Overweight $(n=134)$ & $P$ value \\
\hline Age $(\text { years })^{\mathrm{a}}$ & & $67.6 \pm 12.3$ & $67.1 \pm 10.5$ & $66.9 \pm 10.7$ & $0.897^{\mathrm{d}}$ \\
\hline \multicolumn{6}{|l|}{ Sex } \\
\hline Male & 463 & $43(58.9)$ & $317(73.5)$ & $103(76.9)$ & \multirow[t]{2}{*}{$0.016^{\mathrm{e}}$} \\
\hline Female & 175 & $30(41.1)$ & $114(26.5)$ & $31(23.1)$ & \\
\hline \multicolumn{6}{|l|}{ Cardiovascular disease } \\
\hline Absent & 377 & $45(61.6)$ & $264(61.3)$ & $68(50.7)$ & \multirow[t]{2}{*}{$0.087^{\mathrm{e}}$} \\
\hline Present & 261 & $28(38.4)$ & $167(38.7)$ & $66(49.3)$ & \\
\hline \multicolumn{6}{|l|}{ Diabetes mellitus } \\
\hline Absent & 533 & $63(86.3)$ & $367(85.2)$ & $103(76.9)$ & \multirow[t]{2}{*}{$0.062^{\mathrm{e}}$} \\
\hline Present & 105 & $10(13.7)$ & $64(14.8)$ & $31(23.1)$ & \\
\hline \multicolumn{6}{|l|}{ Chronic renal failure } \\
\hline Absent & 612 & $66(90.4)$ & $418(97.0)$ & $128(95.5)$ & \multirow[t]{2}{*}{$0.031^{\mathrm{e}}$} \\
\hline Present & 26 & $7(9.6)$ & $13(3.0)$ & $6(4.5)$ & \\
\hline \multicolumn{6}{|l|}{ Tumor depth } \\
\hline $\mathrm{T} 1, \mathrm{~T} 2$ & 465 & $51(69.9)$ & $303(70.3)$ & $111(82.8)$ & \multirow[t]{2}{*}{$0.014^{\mathrm{e}}$} \\
\hline $\mathrm{T} 3, \mathrm{~T} 4$ & 173 & $22(30.1)$ & $128(29.7)$ & $23(17.2)$ & \\
\hline \multicolumn{6}{|l|}{ Lymph node metastasis } \\
\hline Absent & 433 & $44(60.3)$ & $291(67.5)$ & $98(73.1)$ & \multirow[t]{2}{*}{$0.160^{\mathrm{e}}$} \\
\hline Present & 205 & $29(39.7)$ & $140(32.5)$ & $36(26.9)$ & \\
\hline \multicolumn{6}{|l|}{ Pathological stage } \\
\hline Stage I & 417 & 45 (61.6) & $276(64.0)$ & $96(71.6)$ & \multirow[t]{3}{*}{$0.187^{\mathrm{e}}$} \\
\hline Stage II & 111 & $10(13.7)$ & $80(18.6)$ & $21(15.7)$ & \\
\hline Stage III & 110 & $18(24.7)$ & $75(17.4)$ & $17(12.7)$ & \\
\hline \multicolumn{6}{|l|}{ CEA $(\mathrm{ng} / \mathrm{ml})^{\mathrm{b}}$} \\
\hline$<5$ & 475 & $43(61.4)$ & $331(78.1)$ & $101(75.4)$ & \multirow[t]{2}{*}{$0.011^{\mathrm{e}}$} \\
\hline$\geq 5$ & 153 & 27 (38.6) & 93 (21.9) & $33(24.6)$ & \\
\hline \multicolumn{6}{|l|}{ CA19-9 $(\mathrm{U} / \mathrm{ml})^{\mathrm{c}}$} \\
\hline$<37$ & 546 & $50(74.6)$ & 373 (88.6) & $123(91.8)$ & \multirow[t]{2}{*}{$0.001^{\mathrm{e}}$} \\
\hline$\geq 37$ & 76 & $17(25.4)$ & $48(11.4)$ & $11(8.2)$ & \\
\hline Serum albumin $(\mathrm{g} / \mathrm{dl})^{\mathrm{a}}$ & & $4.0 \pm 0.6$ & $4.2 \pm 0.4$ & $4.3 \pm 0.4$ & $0.009^{\mathrm{d}}$ \\
\hline $\mathrm{PNI}^{\mathrm{a}}$ & & $47.4 \pm 6.9$ & $50.6 \pm 5.5$ & $51.6 \pm 6.0$ & $<0.001^{\mathrm{d}}$ \\
\hline Hemoglobin $(\mathrm{g} / \mathrm{dl})^{\mathrm{a}}$ & & $12.1 \pm 2.1$ & $13.1 \pm 1.9$ & $13.3 \pm 2.0$ & $<0.001^{\mathrm{d}}$ \\
\hline
\end{tabular}

$B M I$ body mass index, $C E A$ carcinoembryonic antigen, $C A$ carbohydrate antigen, $P N I$ prognostic nutritional index

${ }^{a}$ Values are expressed as means and standard deviations

${ }^{b}$ Data not available for 10 patients

c Data not available for 16 patients

${ }^{\mathrm{d}}$ Indicates value obtained using a one-way analysis of variance (ANOVA)

e Indicates value obtained using the chi-square test

with regard to serum albumin $(P=0.009)$, PNI $(P<0.001)$, and hemoglobin $(P<0.001)$ levels.

\section{Surgical outcomes according to BMI subgroup}

The surgical outcomes as stratified by BMI subgroup are shown in Table 2. The mean duration of surgery was significantly longer in the overweight patients than in the underweight patients (Tukey's test, $P=0.001$ ) and normal weight patients (Tukey's test, $P=0.006$ ). The number of removed lymph nodes was significantly smaller in the overweight patients than in the normal weight patients (Tukey's test, $P=0.027)$. Postoperative complications occurred in 179 patients $(28.1 \%)$; the incidence of postoperative complications was similar between the groups $(P=0.63)$. 
Table 2 Perioperative data according to the BMI group

\begin{tabular}{|c|c|c|c|c|c|}
\hline Variables & Total & Underweight $(n=73)$ & Normal weight $(n=431)$ & Overweight $(n=134)$ & $P$ value \\
\hline Duration of the operation $(\min )^{\mathrm{a}}$ & & $270.0 \pm 72.5$ & $291.3 \pm 96.3$ & $320.0 \pm 99.5$ & $0.001^{\mathrm{d}}$ \\
\hline Blood loss $(\mathrm{ml})^{\mathrm{a}}$ & & $263.8 \pm 329.7$ & $384.7 \pm 885.7$ & $411.8 \pm 414.1$ & $0.380^{\mathrm{d}}$ \\
\hline \multicolumn{6}{|l|}{ Perioperative transfusion } \\
\hline Not performed & 531 & $57(78.1)$ & $361(83.8)$ & $113(84.3)$ & \multirow[t]{2}{*}{$0.452^{\mathrm{e}}$} \\
\hline Performed & 107 & $16(21.9)$ & $70(16.2)$ & $21(15.7)$ & \\
\hline Number of lymph nodes removed ${ }^{a}$ & & $32.1 \pm 18.0$ & $36.7 \pm 18.6$ & $32.0 \pm 18.7$ & $0.012^{\mathrm{d}}$ \\
\hline \multicolumn{6}{|l|}{ Postoperative complication } \\
\hline \multicolumn{6}{|l|}{ Any ${ }^{\mathrm{b}}$} \\
\hline No & 459 & $50(68.5)$ & $315(73.1)$ & $94(70.1)$ & \multirow[t]{2}{*}{$0.630^{\mathrm{e}}$} \\
\hline Yes & 179 & $23(31.5)$ & $116(26.9)$ & $40(29.9)$ & \\
\hline \multicolumn{6}{|l|}{ Surgical } \\
\hline No & 501 & $58(79.5)$ & $340(78.9)$ & $103(76.9)$ & \multirow[t]{2}{*}{$0.865^{\mathrm{e}}$} \\
\hline Yes & 137 & $15(20.5)$ & $91(21.1)$ & $31(23.1)$ & \\
\hline \multicolumn{6}{|l|}{ Infectious } \\
\hline No & 518 & $58(79.5)$ & $355(82.4)$ & $105(78.4)$ & \multirow[t]{2}{*}{$0.538^{\mathrm{e}}$} \\
\hline Yes & 120 & $15(20.5)$ & $76(17.6)$ & 29 (21.6) & \\
\hline \multicolumn{6}{|l|}{ Medical } \\
\hline No & 608 & $68(93.2)$ & $411(95.4)$ & $129(96.3)$ & \multirow[t]{2}{*}{$0.596^{\mathrm{e}}$} \\
\hline Yes & 30 & $5(6.8)$ & $20(4.6)$ & $5(3.7)$ & \\
\hline \multicolumn{6}{|l|}{ Grade 3 or greater $^{\mathrm{c}}$} \\
\hline No & 602 & $69(94.5)$ & $403(93.5)$ & $130(97.0)$ & \multirow[t]{2}{*}{$0.306^{\mathrm{e}}$} \\
\hline Yes & 36 & $4(5.5)$ & $28(6.5)$ & $4(3.0)$ & \\
\hline Length of postoperative hospital stay (days) ${ }^{\mathrm{a}}$ & & $24.6 \pm 18.4$ & $24.7 \pm 24.2$ & $23.9 \pm 14.8$ & $0.929^{\mathrm{d}}$ \\
\hline
\end{tabular}

$B M I$ body mass index

${ }^{\text {a }}$ Values are expressed as means and standard deviations

b Indicates a surgical, infectious, or medical complication

c The grade of the complication was defined according to the Clavien-Dindo classification

${ }^{d}$ Indicates value obtained using a one-way ANOVA

e Indicates value obtained using the chi-square test

\section{Adjuvant chemotherapy}

One hundred and thirty-three patients underwent adjuvant chemotherapy, including 19 (26\%) of 73 underweight patients, $93(21.6 \%)$ of 431 normal weight patients, and 21 $(15.7 \%)$ of 134 overweight patients. Among these 133 patients, treatment was discontinued in 56 patients (42.1\%) for the following reasons: 26 patients, adverse events; 23 patients, tumor relapse; 3 patients, patient refusal; and 4 patients, other reasons. Adjuvant chemotherapy was withdrawn in $8(42.1 \%)$ underweight patients, $39(41.9 \%)$ normal weight patients, and 9 $(42.9 \%)$ overweight patients $(P=0.997)$.

\section{Postoperative survival}

The 5-year OS rate was $66.6 \%$ in the underweight patients, $81.3 \%$ in the normal weight patients, and $79.9 \%$ in the overweight patients $(P=0.001$; Fig. 1a); the 5 -year DSS rate was $82 \%$ in the underweight patients, $88 \%$ in the normal weight patients, and $87.1 \%$ in the overweight patients $(P=0.353$; Fig. $1 b)$.

We next examined the prognostic impact of BMI depending on the cancer stage. The patients were subsequently divided into two groups: those with early-stage cancer (stage I, $n=417$ ) and those with relatively advancedstage cancer (stage II and III, $n=221$ ). The 5 -year OS and DSS rates of the patients with stage I disease were $82.7 \%$ and $97.6 \%$ in the underweight patients, $89.4 \%$ and $97.8 \%$ in the normal weight patients, and $90.4 \%$ and $96.2 \%$ in the overweight patients, respectively (OS, $P=0.028$; DSS, $P=0.761$; Fig. 2), whereas those of the patients with stage II and III disease were $39.5 \%$ and $53.5 \%$ in the underweight patients, $66.9 \%$ and $70.6 \%$ in the normal weight patients, and $51.3 \%$ and $61.7 \%$ in the overweight patients, respectively (OS, $P=0.02$; DSS, $P=0.276$; Fig. 3 ). 
$\mathbf{a}$

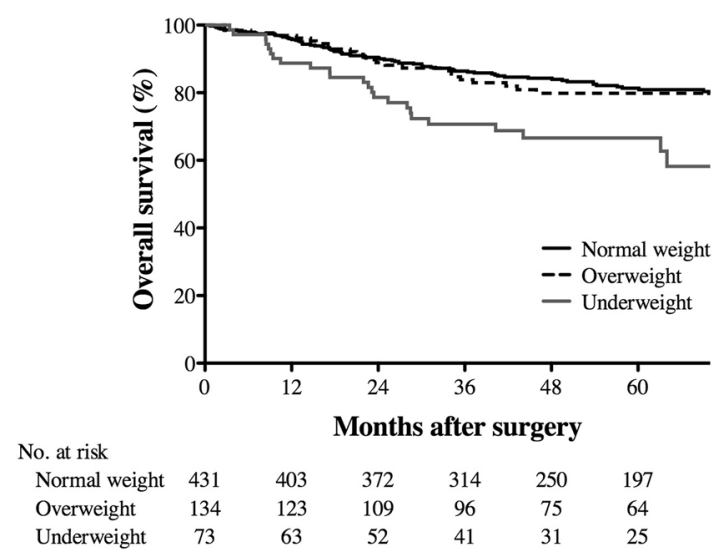

b

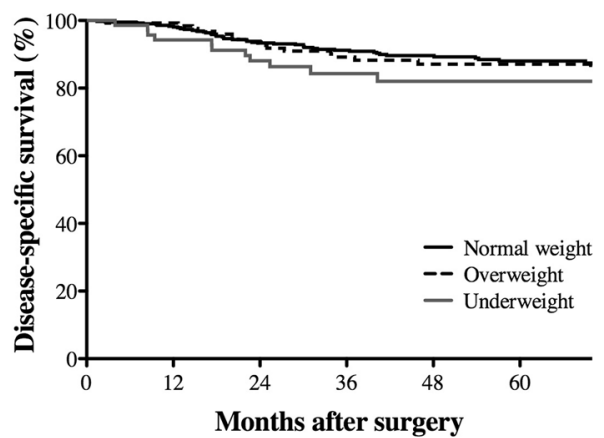

No. at risk

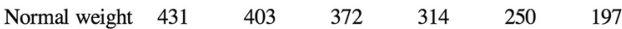
$\begin{array}{lllllll}\text { Overweight } & 134 & 123 & 109 & 96 & 75 & 64\end{array}$

Fig. 1 Kaplan-Meier estimates of overall survival and disease-specific survival according to body mass index (BMI) subgroup. a Overall survival $(P=0.001)$. b Disease-specific survival $(P=0.353)$

$\mathbf{a}$

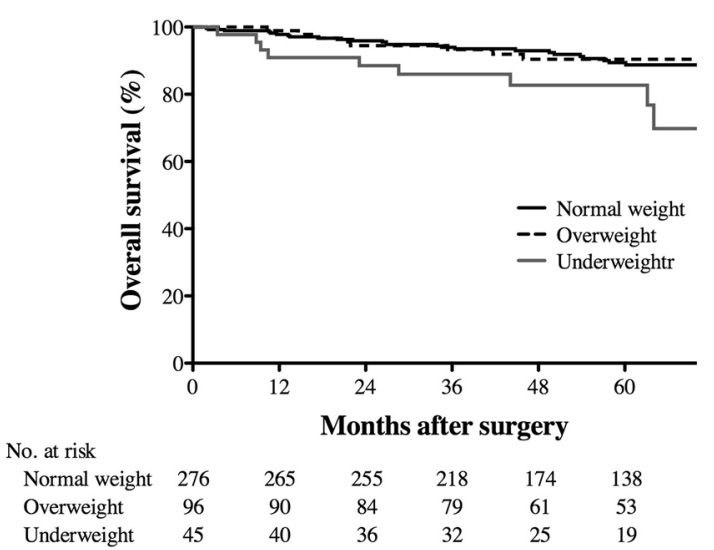

b

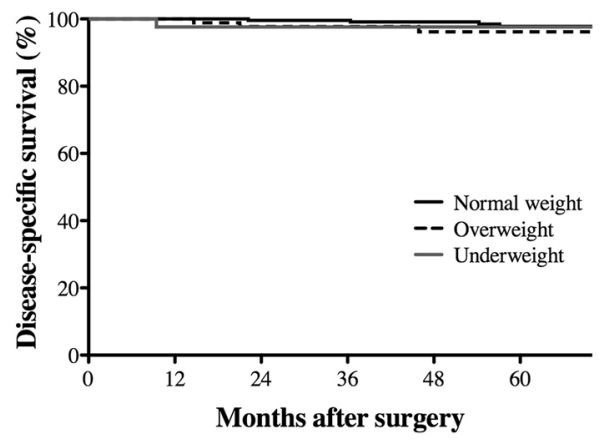

No. at risk

$\begin{array}{lcccccc}\text { Normal weight } & 276 & 265 & 255 & 218 & 174 & 138 \\ \text { Overweight } & 96 & 90 & 84 & 79 & 61 & 53\end{array}$

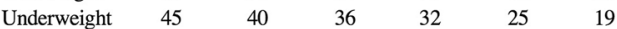

Fig. 2 Kaplan-Meier estimates of overall survival and disease-specific survival according to BMI subgroup among the patients with stage I disease. a Overall survival $(P=0.028)$. b Disease-specific survival $(P=0.761)$

a

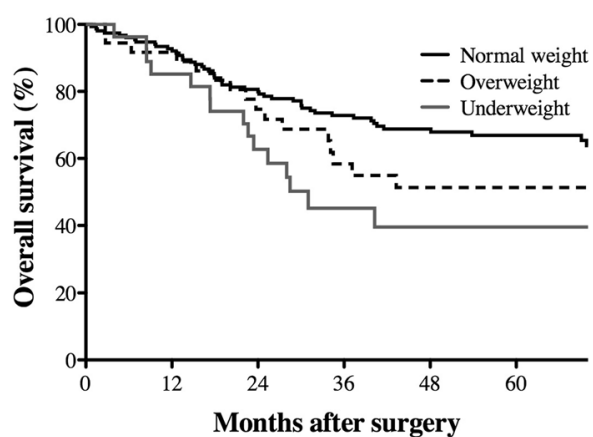

No. at risk

Normat weight 155

Overweight

Underweight

$$
\begin{gathered}
155 \\
38 \\
28
\end{gathered}
$$

Months after surgery

$\begin{array}{ccccc}138 & 117 & 96 & 76 & 59 \\ 33 & 25 & 17 & 14 & 11 \\ 23 & 16 & 9 & 6 & 6\end{array}$

b

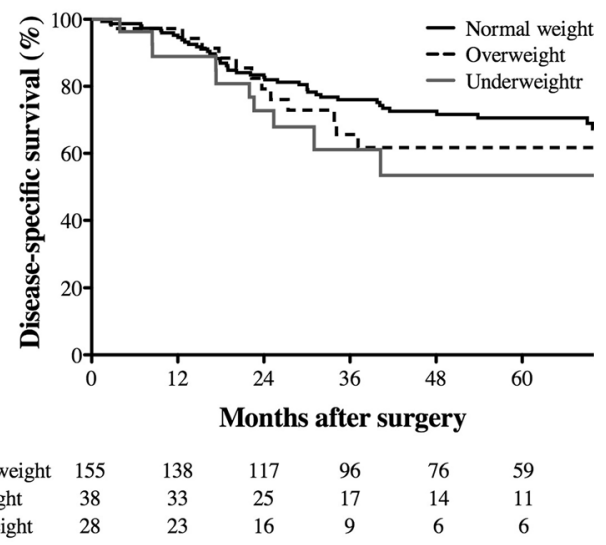

Fig. 3 Kaplan-Meier estimates of overall survival and disease-specific survival according to BMI subgroup among the patients with stage II and III disease. a Overall survival $(P=0.02)$. b Disease-specific survival $(P=0.276)$ 


\section{Cause of death}

At the time of the final follow-up, a total of 131 patients $(20.5 \%)$ had died, including $25(34.2 \%)$ underweight patients, $80(18.6 \%)$ normal weight patients, and 26 $(19.4 \%)$ overweight patients. The cause of death was tumor relapse in $11(15.1 \%), 49(11.4 \%)$, and $15(11.2 \%)$ patients, other cancer in $2(2.7 \%), 10(2.3 \%)$, and 5 $(3.7 \%)$ patients, and cause other than cancer in 12 $(16.4 \%), 21(4.9 \%)$, and $6(4.5 \%)$ patients among the underweight, normal weight, and overweight patients, respectively.

\section{Predictive factors for OS}

According to a univariate analysis of OS, the hazard ratios for being overweight and underweight were 1.08 (95\% CI, $0.693-1.682, \quad P=0.735)$ and $2.247 \quad(95 \% \quad \mathrm{CI}$, 1.432-3.526, $P<0.001$ ), respectively. The multivariate analysis demonstrated that an underweight status $(P=0.02)$, chronic renal failure $(P=0.001)$, tumor depth $(P<0.001)$, lymph node metastasis $(P<0.001)$, CEA $(P=0.024)$, perioperative transfusion $(P=0.039)$, and postoperative complications $(P=0.018)$ were each independent prognostic factors for OS (Table 3 ).

We finally performed a multivariate survival analysis among the patients with stage II and III disease, and thus found underweight status to not be an independent predictor of OS (Table 4).

\section{Discussion}

The present study demonstrated that being underweight is a reliable predictor of a worse prognosis among gastric cancer patients. Many studies have examined the relationship between BMI and prognosis in gastric cancer patients [5-9]. However, the prognostic significance for gastric cancer patients of being underweight remains unknown. In the present study, we found that the OS rate was significantly lower among the underweight patients than among the normal weight and overweight patients. In addition, previous studies have reported various predictors of the prognosis of gastric cancer patients, including tumor depth, lymph node metastasis, distant metastasis, tumor markers, and postoperative complications [21, 22]. Importantly, the multivariate analysis performed in the present study demonstrated that, in addition to these factors, being underweight is an independent predictor of OS (hazard ratio, 1.797; $95 \% \mathrm{CI}, 1.097-2.943 ; P=0.02$ ).

Previous studies have also reported that being underweight is associated with an increased risk of cancer recurrence $[10,11,14]$, and others have shown that being underweight is a factor for non-cancer death [13]. In the present study, we investigated the detailed causes of the poor prognoses of underweight patients and determined several important findings. First, the present underweight patients exhibited a higher risk of non-cancer death. Dignam et al. demonstrated a 3.47-fold increase in the hazard of death attributed to non-cancer causes among underweight breast cancer patients relative to that observed in normal weight breast cancer patients [13]. In the current study, in all $12(16.4 \%)$ underweight patients died of a cause other than cancer, whereas $21(4.9 \%)$ normal weight patients and $6(4.5 \%)$ overweight patients died of causes other than cancer $(P<0.001)$. These causes included infection in $6(8.2 \%)$ underweight patients, $7(1.6 \%)$ normal weight patients, and $3(2.2 \%)$ overweight patients, with cardiac events in $1(1.4 \%), 6(1.4 \%)$, and $3(2.2 \%)$ patients, cerebral vascular events in $2(2.7 \%), 2(0.5 \%)$, and 0 patients, other causes in $1(1.4 \%), 4(0.9 \%)$, and 0 patients, and unknown causes in $2(2.7 \%), 2(0.5 \%)$, and 0 patients, respectively. Furthermore, the OS rate was significantly lower among the underweight patients than the normal weight or overweight patients among those with stage I disease, and most of these patients died of causes other than cancer (data not shown). These results suggest that a preoperative underweight status may increase the risk of non-cancer death, particularly regarding death from infection.

Second, on the other hand, being underweight was found to have little impact on death from gastric cancer. Several studies have reported an increased rate of cancer death among underweight cancer patients, including those with colon cancer, nasopharyngeal carcinoma, and breast cancer, suggesting that being underweight is associated with increased tumor aggressiveness and that this may contribute to both cancer recurrence and metastasis $[10,12$, 14]. In the present study, the underweight patients had more aggressive tumors, as evidenced by high tumor marker levels, than the normal weight and overweight patients. In addition, the underweight patients had a significantly lower OS rate than the normal weight patients among those with relatively advanced-stage disease, and many of these patients died of a relapse of gastric cancer (data not shown). These findings suggest that an underweight status may be associated with a higher risk of gastric cancer recurrence and death. However, the DSS rate of the underweight patients did not differ from that of the other two groups. Furthermore, a multivariate analysis showed an underweight status to not be an independent predictor of OS among the patients with stage II and III disease. These results indicate that being underweight in itself may not increase the risk of gastric cancer death. Taken together, our data suggest that a preoperative underweight status carries a higher risk of non-cancer death 
Table 3 Results of the analysis of the prognostic factors for overall survival

\begin{tabular}{|c|c|c|c|c|}
\hline \multirow[t]{2}{*}{ Variables } & \multicolumn{2}{|l|}{ Univariate analysis } & \multicolumn{2}{|l|}{ Multivariate analysis } \\
\hline & Hazard ratio $(95 \% \mathrm{CI})$ & $P$ value & Hazard ratio $(95 \% \mathrm{CI})$ & $P$ value \\
\hline Age & $1.031(1.012-1.049)$ & 0.001 & $1.017(0.998-1.036)$ & 0.083 \\
\hline \multicolumn{5}{|l|}{ Sex } \\
\hline Female & 1 & 0.452 & - & - \\
\hline Male & $1.164(0.784-1.727)$ & & & \\
\hline \multicolumn{5}{|c|}{ Cardiovascular disease } \\
\hline Absent & 1 & 0.011 & 1 & 0.371 \\
\hline Present & $1.563(1.110-2.203)$ & & $1.186(0.816-1.725)$ & \\
\hline \multicolumn{5}{|l|}{ Diabetes mellitus } \\
\hline Absent & 1 & 0.057 & - & - \\
\hline Present & $1.502(0.989-2.283)$ & & & \\
\hline \multicolumn{5}{|c|}{ Chronic renal failure } \\
\hline Absent & 1 & $<0.001$ & 1 & 0.001 \\
\hline Present & $3.365(1.856-6.102)$ & & $3.013(1.581-5.742)$ & \\
\hline \multicolumn{5}{|l|}{ Tumor depth } \\
\hline $\mathrm{T} 1, \mathrm{~T} 2$ & 1 & $<0.001$ & 1 & $<0.001$ \\
\hline $\mathrm{T} 3, \mathrm{~T} 4$ & $3.687(2.614-5.199)$ & & $2.261(1.476-3.463)$ & \\
\hline \multicolumn{5}{|c|}{ Lymph node metastasis } \\
\hline Absent & 1 & $<0.001$ & 1 & $<0.001$ \\
\hline Present & $3.948(2.780-5.608)$ & & $2.485(1.623-3.805)$ & \\
\hline \multicolumn{5}{|l|}{ CEA (ng/ml) } \\
\hline$<5$ & 1 & $<0.001$ & 1 & 0.024 \\
\hline$\geq 5$ & $2.581(1.815-3.670)$ & & $1.568(1.061-2.316)$ & \\
\hline \multicolumn{5}{|l|}{ CA19-9 (U/ml) } \\
\hline$<37$ & 1 & $<0.001$ & 1 & 0.230 \\
\hline$\geq 37$ & $2.624(1.741-3.956)$ & & $1.333(0.833-2.132)$ & \\
\hline \multicolumn{5}{|c|}{ Perioperative transfusion } \\
\hline Not performed & 1 & $<0.001$ & 1 & 0.039 \\
\hline Performed & $3.076(2.135-4.432)$ & & $1.518(1.022-2.254)$ & \\
\hline \multicolumn{5}{|c|}{ Postoperative complication (any) ${ }^{\mathrm{a}}$} \\
\hline No & 1 & $<0.001$ & 1 & 0.018 \\
\hline Yes & $2.012(1.418-2.857)$ & & $1.562(1.080-2.260)$ & \\
\hline \multicolumn{5}{|l|}{ BMI group } \\
\hline Normal weight & 1 & & 1 & \\
\hline Overweight & $1.080(0.693-1.682)$ & 0.735 & $1.396(0.884-2.204)$ & 0.153 \\
\hline Underweight & $2.247(1.432-3.526)$ & $<0.001$ & $1.797(1.097-2.943)$ & 0.020 \\
\hline
\end{tabular}

but not of gastric cancer death. However, further investigations are required to fully understand the mechanisms involved in being underweight and its association with biological behavior of gastric cancer and patient survival, as the number of patients with stage II and III disease in the present study was relatively small.

Furthermore, previous studies have reported that a poor nutritional status is associated with increased toxicity and a decreased response to anti-cancer therapy [15, 23, 24]. Overweight and obese patients may have larger nutritional stores and have been shown to exhibit significantly lower rates of treatment-related toxicity, whereas underweight patients display higher toxicity rates. In the present study, the rate of withdrawal of adjuvant chemotherapy because of adverse events did not differ among the groups (data not shown). Therefore, the worse prognoses of the underweight patients were not likely the result of withdrawal of adjuvant chemotherapy. However, the present study is also associated with various limitations. First, this study is retrospective in nature, and the number of patients who received 
Table 4 Results of the multivariate analysis of the prognostic factors for overall survival among patients with stage II and III disease

\begin{tabular}{|c|c|c|}
\hline Variables & Hazard ratio $(95 \% \mathrm{CI})$ & $P$ value \\
\hline \multicolumn{3}{|c|}{ Chronic renal failure } \\
\hline Absent & 1 & \multirow[t]{2}{*}{0.167} \\
\hline Present & $2.162(0.724-6.456)$ & \\
\hline \multicolumn{3}{|c|}{ Lymph node metastasis } \\
\hline Absent & 1 & \multirow[t]{2}{*}{0.022} \\
\hline Present & $2.400(1.136-5.069)$ & \\
\hline \multicolumn{3}{|l|}{ CEA (ng/ml) } \\
\hline$<5$ & 1 & \multirow[t]{2}{*}{0.139} \\
\hline$\geq 5$ & $1.488(0.879-2.522)$ & \\
\hline \multicolumn{3}{|l|}{ CA19-9 (U/ml) } \\
\hline$<37$ & 1 & \multirow[t]{2}{*}{0.037} \\
\hline$\geq 37$ & $1.896(1.038-3.464)$ & \\
\hline \multicolumn{3}{|c|}{ Perioperative transfusion } \\
\hline Not performed & 1 & \multirow[t]{2}{*}{0.274} \\
\hline Performed & $1.309(0.808-2.120)$ & \\
\hline \multicolumn{3}{|c|}{ Postoperative complication (any) $^{\mathrm{a}}$} \\
\hline No & 1 & \multirow[t]{2}{*}{0.002} \\
\hline Yes & $2.093(1.324-3.309)$ & \\
\hline \multicolumn{3}{|l|}{ BMI group } \\
\hline Normal weight & 1 & \\
\hline Overweight & $1.368(0.744-2.516)$ & 0.313 \\
\hline Underweight & $1.442(0.757-2.748)$ & 0.265 \\
\hline
\end{tabular}

$C I$ confidence interval, CEA carcinoembryonic antigen, $C A$ carbohydrate antigen, $B M I$ body mass index

${ }^{\text {a }}$ Indicates a surgical, infectious, or medical complication

adjuvant chemotherapy was relatively small. Second, postoperative body weight was not evaluated. A recent study demonstrated postoperative body weight loss to be the most important risk factor for compliance with adjuvant chemotherapy in gastric cancer patients [25]. Further studies are therefore needed to elucidate the relationship between BMI and compliance with adjuvant chemotherapy.

In addition, a previous study noted that underweight patients may include both undernourished patients and active, healthy individuals with an inherited lean body type, although at least some underweight patients are undernourished [14]. In the present study, serum albumin, PNI, and hemoglobin levels were significantly lower in the underweight patients than in the other patients. Therefore, the underweight category appears to include more undernourished patients than other categories.

Given that a preoperative underweight status is associated with a higher risk of non-cancer death, perioperative nutritional intervention may therefore reduce non-cancer death, such as death from infection, thereby improving the prognoses of underweight patients. Several trials have evaluated the effects of different nutrients on the short-term outcomes following various types of gastrointestinal surgery. For example, some studies have shown that perioperative nutrient supplementation significantly reduces the incidence of postoperative complications and length of hospital stay [26, 27], whereas others have failed to demonstrate any benefits from nutrient therapy [28, 29]. Therefore, whether perioperative nutritional intervention in underweight patients with gastric cancer can improve their long-term outcome remains unclear. Further randomized prospective studies are therefore required to clarify this issue.

In conclusion, the present study demonstrated that being underweight is a simple and reliable predictor of a worse long-term outcome among gastric cancer patients. A preoperative underweight status may be associated with a higher risk of non-cancer death. Based on these results, we therefore suggest that the BMI should be included in the preoperative routine assessment of patients with gastric cancer.

\section{Compliance with ethical standards}

Conflict of interest None of the authors has any financial conflicts to disclose in association with this study.

\section{References}

1. Hennessey DB, Burke JP, Ni-Dhonochu T, Shields C, Winter DC, Mealy K. Preoperative hypoalbuminemia is an independent risk factor for the development of surgical site infection following gastrointestinal surgery: a multi-institutional study. Ann Surg. 2010;252:325-9.

2. Schwegler I, von Holzen A, Gutzwiller JP, Schlumpf R, Muhlebach S, Stanga Z. Nutritional risk is a clinical predictor of postoperative mortality and morbidity in surgery for colorectal cancer. Br J Surg. 2010;97:92-7.

3. Migita K, Takayama T, Saeki K, Matsumoto S, Wakatsuki K, Enomoto K, et al. The prognostic nutritional index predicts longterm outcomes of gastric cancer patients independent of tumor stage. Ann Surg Oncol. 2013;20:2647-54.

4. Lien YC, Hsieh CC, Wu YC, Hsu HS, Hsu WH, Wang LS, et al. Preoperative serum albumin level is a prognostic indicator for adenocarcinoma of the gastric cardia. J Gastrointest Surg. 2004;8:1041-8.

5. Dhar DK, Kubota H, Tachibana M, Kotoh T, Tabara H, Masunaga $\mathrm{R}$, et al. Body mass index determines the success of lymph node dissection and predicts the outcome of gastric carcinoma patients. Oncology. 2000;59:18-23.

6. Barry JD, Blackshaw GR, Edwards P, Lewis WG, Murphy P, Hodzovic I, et al. Western body mass indices need not compromise outcomes after modified D2 gastrectomy for carcinoma. Gastric Cancer. 2003;6:80-5.

7. Bickenbach KA, Denton B, Gonen M, Brennan MF, Coit DG, Strong VE. Impact of obesity on perioperative complications and long-term survival of patients with gastric cancer. Ann Surg Oncol. 2013;20:780-7. 
8. Tokunaga M, Hiki N, Fukunaga T, Ohyama S, Yamaguchi T, Nakajima T. Better 5-year survival rate following curative gastrectomy in overweight patients. Ann Surg Oncol. 2009;16:3245-51.

9. Kong F, Li H, Fan Y, Zhang X, Cao S, Yu J, et al. Overweight patients achieve ideal body weight following curative gastrectomy resulting in better long-term prognosis. Obes Surg. 2013;23:650-6.

10. Sinicrope FA, Foster NR, Yothers G, Benson A, Seitz JF, Labianca $\mathrm{R}$, et al. Body mass index at diagnosis and survival among colon cancer patients enrolled in clinical trials of adjuvant chemotherapy. Cancer (Phila). 2013;119:1528-36.

11. Ishizuka M, Kubota K, Kita J, Shimoda M, Kato M, Sawada T. Underweight patients show an increased rate of postoperative death after surgery for hepatocellular carcinoma. J Surg Oncol. 2011;104:809-13.

12. Huang PY, Wang CT, Cao KJ, Guo X, Guo L, Mo HY, et al. Pretreatment body mass index as an independent prognostic factor in patients with locoregionally advanced nasopharyngeal carcinoma treated with chemoradiotherapy: findings from a randomised trial. Eur J Cancer. 2013;49:1923-31.

13. Dignam JJ, Wieand K, Johnson KA, Fisher B, Xu L, Mamounas EP. Obesity, tamoxifen use, and outcomes in women with estrogen receptor-positive early-stage breast cancer. J Natl Cancer Inst. 2003;95:1467-76.

14. Moon HG, Han W, Noh DY. Underweight and breast cancer recurrence and death: a report from the Korean Breast Cancer Society. J Clin Oncol. 2009;27:5899-905.

15. Kizer NT, Thaker PH, Gao F, Zighelboim I, Powell MA, Rader JS, et al. The effects of body mass index on complications and survival outcomes in patients with cervical carcinoma undergoing curative chemoradiation therapy. Cancer (Phila). 2010;117:948-56.

16. Liu JY, Li YH, Liu ZW, Zhang ZL, Ye YL, Yao K, et al. Influence of body mass index on oncological outcomes in patients with upper urinary tract urothelial carcinoma treated with radical nephroureterectomy. Int J Urol. 2014;21:136-42.

17. Alici S, Kaya S, Izmirli M, Tuncer I, Dogan E, Ozbek H, et al. Analysis of survival factors in patients with advanced-stage gastric adenocarcinoma. Med Sci Monit. 2006;12:CR221-9.

18. WHO Expert Consultation. Appropriate body-mass index for Asian populations and its implications for policy and intervention strategies. Lancet. 2004;363:157-63.
19. Sobin L, Gospodarowicz M, Wittekind C, editors. International Union Against Cancer (UICC). TNM classification of malignant tumors. 7th ed. New York: Wiley-Blackwell; 2010.

20. Dindo D, Demartines N, Clavien PA. Classification of surgical complications: a new proposal with evaluation in a cohort of 6336 patients and results of a survey. Ann Surg. 2004;240:205-13.

21. Nakane Y, Okamura S, Akehira K, Boku T, Okusa T, Tanaka K, et al. Correlation of preoperative carcinoembryonic antigen levels and prognosis of gastric cancer patients. Cancer (Phila). 1994;73:2703-8.

22. Sierzega M, Kolodziejczyk P, Kulig J. Impact of anastomotic leakage on long-term survival after total gastrectomy for carcinoma of the stomach. Br J Surg. 2010;97:1035-42.

23. Dewys WD, Begg C, Lavin PT, Band PR, Bennett JM, Bertino JR, et al. Prognostic effect of weight loss prior to chemotherapy in cancer patients. Eastern Cooperative Oncology Group. Am J Med. 1980;69:491-7.

24. Meyerhardt JA, Catalano PJ, Haller DG, Mayer RJ, Benson AB III, Macdonald JS, et al. Influence of body mass index on outcomes and treatment-related toxicity in patients with colon carcinoma. Cancer (Phila). 2003;98:484-95.

25. Aoyama T, Yoshikawa T, Shirai J, Hayashi T, Yamada T, Tsuchida $\mathrm{K}$, et al. Body weight loss after surgery is an independent risk factor for continuation of S-1 adjuvant chemotherapy for gastric cancer. Ann Surg Oncol. 2013;20:2000-6.

26. Senkal M, Zumtobel V, Bauer KH, Marpe B, Wolfram G, Frei A, et al. Outcome and cost-effectiveness of perioperative enteral immunonutrition in patients undergoing elective upper gastrointestinal tract surgery: a prospective randomized study. Arch Surg. 1999;134:1309-16.

27. Braga M, Gianotti L, Vignali A, Carlo VD. Preoperative oral arginine and n-3 fatty acid supplementation improves the immunometabolic host response and outcome after colorectal resection for cancer. Surgery (St. Louis). 2002;132:805-14.

28. Sultan J, Griffin SM, Di Franco F, Kirby JA, Shenton BK, Seal $\mathrm{CJ}$, et al. Randomized clinical trial of omega-3 fatty acid-supplemented enteral nutrition versus standard enteral nutrition in patients undergoing oesophagogastric cancer surgery. Br J Surg. 2012;99:346-55.

29. Fujitani K, Tsujinaka T, Fujita J, Miyashiro I, Imamura H, Kimura Y, et al. Prospective randomized trial of preoperative enteral immunonutrition followed by elective total gastrectomy for gastric cancer. Br J Surg. 2012;99:621-9. 